\title{
COVID-19 e a aceleração do achatamento do horizonte de expectativa
}

\author{
COVID-19 and the accelerated flattening of the horizon of expectation
}

\section{Mariana Lins Costa*}

Resumo: 0 presente ensaio consiste numa apropriação do argumento desenvolvido por Paulo Arantes no seu ensaio "O novo tempo do mundo" de modo a refletir sobre o cenário da pandemia no contexto social brasileiro.

Palavras-chave: Pandemia; Novo tempo do mundo; Sacrifício

Abstract: This essay consists of an appropriation of Paulo Arantes's argument developed in his essay "The new time of the world". The purpose is to reflect upon the pandemic scenario in the Brazilian social context.

Keywords: Pandemic; New World Time; Sacrifice

God save the queen/ Her fascist regime/ It made you a moron/ A potential H bomb/ [...] Oh, God save history/God save your mad parade/ [...] When there's no future, how can there be sin? / [...] No future/ No future/ No future for you/ No future/ No future/ No future for $\mathrm{me}^{1}$ (Sex Pistols. "God Save the Queen")

É realmente necessário ser honesto até o ponto de supor, conforme parece sugerir Paulo Arantes na sua apropriação de Koselleck, que o futuro é coisa do passado? É realmente o caso de considerar, junto a Nietzsche, que a “exploração' não é própria a uma sociedade corrompida, imperfeita e primitiva", mas antes o "princípio básico da sociedade"? É mesmo o caso de pensar seriamente que Nietzsche não foi longe demais quando supôs que "a vida mesma é essencialmente apropriação, ofensa, sujeição do que é estranho e mais fraco, opressão, dureza, imposição de formas próprias, incorporação e, no mínimo e mais comedido, exploração"2? Seria esta suposição nietzschiana, expressa de modo tão simples e direto, a verdade que o Covid-19 nos esfregará na cara, a despeito das nossas mais sinceras inclinações humanistas? Será que o que cabe nós, intelectuais das ciências humanas, nesse momento, é considerar seriamente que a filosofia da história, com sua profecia esclarecida de que a justiça política e social universal é algo como um fim inexorável de tão razoável, não seja, talvez, muito mais do que mero embuste? Um conto da carochinha apenas um tanto mais elaborado do que o da segunda vinda? Ao mesmo tempo em que talvez mais fantasioso e fantástico no sentido de que sequer nas maravilhas narradas nos últimos livros do Apocalipse, a Nova Jerusalém é prometida para todos? Será apropriado considerar que, em meio a esse nosso cenário, estamos e estaremos cada vez mais excluídos de uma Nova Jerusalém Hi-Tec, dado

\footnotetext{
1 "Deus salve a rainha/ Seu regime fascista/ Que fez de você um imbecil/ Uma bomba H em potencial/ [...]/ Oh, Deus salve a história/ Deus salve a sua passeata alucinada/ [...] Quando não há futuro, como pode haver pecado?/ [...] Não há futuro/ Não há futuro/ Não há futuro para você/ Não há futuro/ Não há futuro/ Não há futuro para mim". Disponível em: https://www.youtube.com/watch?v=yqrAPOZxgzU. Acesso 27 de abril de 2020.

2 NIETZSCHE, Além do bem e do mal, 154-5.
}

* Pós-doutoranda em Filosofia na Universidade Federal de Sergipe, São Cristóvão, SE. E-mail: marianalins @hotmail.com ORCID: https://orcid.org/0000-0003-4909-3757 
que o ticket de entrada, diferentemente do cristão e iluminista, não é moral, mas tão somente econômico? Será que a grande novidade, no que diz respeito a nós intelectuais das ciências humanas, é que as águas tornadas amargas pela estrela do Absinto estão nesse momento prestes a nos engolir, quando antes, bem ou mal, em melhores ou piores condições, estávamos relativamente resguardados pelos muros das universidades? E que é por isso, sobretudo, que estamos bradando mais alto? Por que seremos também engolidos? Por que corremos o risco real de virar estatística da pior espécie? E isso quando pouco antes estávamos com a nossa pele supostamente a salvo? Não seria o caso de considerar que a eleição de Bolsonaro é antes um componente de aceleração do achatamento do nosso horizonte de expectativas; um componente que já era, de qualquer modo, inexorável e inexorável há muito tempo? Em sendo assim, por que uma ameaça direta à própria existência, seria motivo de uma maior solidariedade? Como o instinto de sobrevivência, ainda mais aguçado, ainda mais atiçado, pode vir a gerar algo como o seu oposto, o altruísmo, uma "solidariedade genérica"? Ou para falar em termos menos morais: como o risco iminente e concreto à vida nua pode vir a gerar, $\mathrm{o}$ que, ao menos no que diz respeito ao nosso país, nunca foi capaz de gerar: a responsabilidade política mutua entre concidadãos miseráveis e não miseráveis, esclarecidos e não esclarecidos, apocalípticos e utópicos, fascistas e antifascistas? Antes não seria o contrário? Se a minha vida se encontra em risco por conta de uma massa de miseráveis - que agora sequer poderá respirar e salivar em paz, sem que seja vista como uma bomba em potencial - então exterminá-la ou abandoná-la ao extermínio não se torna com isso, dito de modo nu e cru, apenas uma extensão do princípio de legítima defesa? Lembremos do que disse Hannah Arendt, ao considerar que a expressão "massacre administrativo" seria melhor adequada do que "genocídio" para designar o que ocorreu contra os judeus e demais "tipos indesejáveis" sob o governo de Hitler. Segundo ela, tal expressão não só teria "a virtude de dissipar a suposição de que tais atos só podem ser cometidos contra nações estrangeiras ou de raça diferente", como também daria conta de abranger os assassinatos em massa dos "doentes incuráveis", assassinatos que foram pretendidos pelos seus perpetradores como espécie de "morte misericordiosa"3. Aqui, porém, nos tristes trópicos desprovidos da técnica e disciplina alemães, todos sabemos que não só não precisará haver incurabilidade, como nunca houve misericórdia. Bradamos nas redes sociais como se houvesse algo de novo no mundo, algo de errado, quando o mundo talvez apenas esteja a seguir o seu fluxo de sempre só que em velocidade mais acelerada. Acreditamos demais em Hegel, de que somente o racional é real. "Nós homens do conhecimento de nós mesmos somos desconhecidos"4. Por nunca termos escutado as dozes badaladas do meio-dia, supomos que, por isso, não poderíamos estar perto da meia-noite.

Ante tal perspectiva, parece que estou incorrendo no que Vladmir Safatle, em artigo recente para o jornal EL Pais, compreende como o "pior erro" de análise do nosso momento atual: o de, por estar com os "olhos submersos na lógica repetitiva do 'sempre foi assim"', não ser capaz de identificar que, para além da "conhecida máquina necropolítica do estado brasileiro", estamos diante de algo novo, no caso: "Trata-se da explosão de rituais públicos de autossacrifício e de violência" 5 . Ora, de fato, é muito chocante, como coloca Safatle, que numa área nobre da desenvolvida São Paulo, pessoas recebam balas de chumbinho por estarem pacificamente exercendo a sua responsabilidade cívica de bater panelas - e que isso de fato pareça mesmo um prenúncio de uma violência mais direta entre pessoas que até então reprimiam os seus impulsos violentos não desviados de sua meta sob os códigos e benesses da civilidade. Seja como for, no chamado Brasil real, longe dos grandes centros urbanos e dos holofotes, o simples olhar atravessado ou supostamente para onde não deve é, e não tão

\footnotetext{
${ }^{3}$ ARENDT, Eichmann em Jerusalém, 172.

${ }^{4}$ NIETZSCHE, Genealogia da moral, 23.

5 SAFATLE. Preparar-se para a guerra. Disponível em: https://brasil.elpais.com/opiniao/2020-04-20/prepararse-para-a-guerra.html Acesso: 20 de abril de 2020.
} 
raramente assim, motivo suficiente para uma bala que nunca foi de chumbinho ou, na ausência do acesso a uma arma de fogo, para um golpe de facão ou espancamento até a morte. Isso para não mencionar o chamado "Tribunal do crime" praticamente uma instituição em alguns dos bairros pouco abastados da mesma São Paulo ou a pena de morte para o adultério feminino aplicada com a mesma rigidez da época da lei do Talião em não poucas comunidades do nosso grande e desconhecido Brasil. Mas de fato se os não tão pretos de não tão pobres e de não tão nordestinos começarem a se matar usando de violência direta, por exemplo, em plena Avenida Paulista, estaremos realmente diante de uma espécie de tremor tectônico porque aí até o que no Brasil não é Haiti vira terra arrasada (o que, de todo modo, o "comunista" coronavírus parece estar a preparar). Ainda assim, não consigo ver uma diferença de substância, só de grau - muito embora, não esteja, com isso, intentando negar que esse grau excessivo tenha tornado o que antes era ordinário, comum, cultural numa realidade que parece mais fantástica do que a própria literatura fantástica. Seja como for, após testemunhar algumas cenas e ouvir tantos relatos sobre as humilhações morais (quando não sexuais) e a exploração econômica estrutural sofridas pelas empregadas domésticas das classes médias e altas, para me referir às condições de uma única classe trabalhadora, infelizmente não consigo me surpreender com a zombaria aberta à dor e ao desespero do outro - talvez ela esteja até se tornando mais democrática ao, por exemplo, incluir as prenunciadas mortes e pauperização em massa de nós, trabalhadores das faculdades superiores.

Compreendo que o ponto que seja chocante nessa nossa atual realidade fantástica não é a novidade de uma violência que não havia, mas o fato de essa ter se tornado bandeira, uma causa. Compreendo que a novidade não é exatamente o desprezo declarado à "preocupação moderna com as vítimas" - que, sobretudo após a derrota do nazismo, parecia um pacto indissolúvel entre os cidadãos do ocidente e zonas periféricas -, mas sim o fato de que esse desprezo tenha saído dos discursos privados entre amigos, conhecidos e familiares (para não mencionar aqui a questão da necropolítica, como diz Safatle, via Achille Mbembe) para ganhar as redes sociais e declarações midiáticas também de indivíduos em importantes cargos públicos e posições de poder. E o que é mais grave, conforme parece defender Safatle na entrevista dada a revista Carta Capital publicada no dia 27 de abril: é realmente um passo para além do abismo que esse desprezo tenha se transformado numa ideologia capaz de tornar sangue uma guerra cultural que conforme também parece sugerir coloca na condição de pretos e pobres, indivíduos com diplomas e propriedades privadas suficiente satisfatórias por estarem agora enquadrados sob o "crime" de "esquerdistas". Não estou defendendo que uma tal ascensão deveras inédita ao poder não seja suficientemente terrível ou que não conduza a políticas públicas ainda mais assassinas, à formação de turbas de machos relativamente brancos com sangue nas ventas já que além de tudo estão munidos de uma ideologia que lhes legitima e instiga o ataque; e tudo isso, em tempos que, diga-se de passagem, nenhuma política pública parece ser efetivamente capaz de impedir um número catastrófico de mortes em massa. 0 ponto que pretendo destacar é mais simples e outro: o de que discursos politicamente corretos (como o "Eu avisei") não têm força revolucionária real que seja capaz de prescindir da ação e, portanto, em alguma medida, do autossacrifício deliberado que, ao que parece, Safatle só considera condizente a uma prática exclusivamente fascista. Não consigo compreender como o eleitorado natural" da esquerda - os, segundo ele, $30 \%$ opostos aos $30 \%$ bolsonaristas - possa estar "com a garganta travada", a ponto de não conseguir "nem gritar"6. Pois se houve, conforme ele diz, "15 dias praticamente de panelaço ininterrupto, espontâneo" e, ninguém, fez com isso nada, o ponto não é tanto o de não se estar gritando, mas o de não se estar sendo ouvido e talvez sobretudo o de não se estar agindo. Que fiquemos a falar, a gritar e a falar - sobre Bolsonaro declarar não ser coveiro ou sobre o

6 Disponível em: https://www.cartacapital.com.br/politica/bolsonaro-se-ve-a-frente-de-uma-revolucao-emmarcha-e-nao-vai-parar/. Acesso: 27 de abril de 2020. 
humanitarismo mal-ajambrado de algum outro representante político de discurso e partido mais ponderados, dada a sua diligência em preparar um número de leitos de UTI que nem de longe será suficiente; que gritemos isso e aquilo, como todos sabemos, em nada muda a expectativa de que ou morreremos ou veremos muitos morrer- só que dessa vez aos montes para além dos morros e das vastas terras nacionais onde o diabo perdeu tantas e tantas botas. Salvo a cafonice realmente bestial dos manifestantes pró-bolsonaro, para fazer aqui uma adaptação de uma observação a meu ver muito profunda de Fernanda Young, infelizmente não consigo ver nada de essencialmente novo nessa falta de humanitarismo, solidariedade, bom senso e ponderação tornada bandeira e ostentada com orgulho nos tons verde e amarelo, por aqueles que agora, se Safatle está correto, preparam-se para usar "camisas pretas". Na realidade, só consigo me lembrar das palavras de Matheus 10:26: "Portanto, não os temais; porque nada há encoberto que não haja de revelar-se, nem oculto que não haja de saber-se."

Em seu ensaio "O novo tempo do mundo", Paulo Arantes faz a pergunta sobre qual seria a hora do mundo em que nos encontramos. Segundo ele, a expressão tempo do mundo, cunhada pelo historiador Wolfram Eberhard, sugere "a existência de algo como um clima internacional, suficientemente persuasivo para influenciar escolhas sociais e decisões políticas em arenas sociais mais restritas"7 ou, dito de modo mais simples, indica "o contexto mundial de uma época determinada". Conforme o exemplo que coloca: por mais que a "França do século XVIII e Índia do século XX" compartilhem "certas características estruturais" são "incomparáveis na medida em que os respectivos contextos mundiais não poderiam ser mais distantes" 8 . A esse conceito acrescenta, a partir da leitura de Fernand Braudel, a ideia de "hora fatídica do relógio do mundo" - isto é, haveria algo como um momento histórico, marcado por determinados eventos world-historical, em que se daria uma "troca de comando", uma espécie de "era de transição congestionada por guerras e revoluções, de uma hegemonia mundial à outra" .

Uma das horas fatídicas do relógio do mundo, a nós mais relevante, teria badalado com as grandes navegações e, no nosso caso de periféricos, com a crise do "Antigo sistema colonial que levou à ruptura do vínculo com a Metrópole"10. Apropriando-se do esquema metateórico de Koselleck, Arantes irá assinalar que a novidade dos Tempos Modernos pode ser definida pelo "par assimétrico constituído pelo contraponto indissolúvel entre Espaço de experiência e Horizonte de expectativa"11. Dito de outro modo: o parâmetro fundador dos novos tempos diria respeito ao "deslocamento de todo um Horizonte de Expectativa"12. Se, conforme escreve Koselleck, citado por Arantes, a "história da Cristandade, até o século XVI, é uma história [...] de uma contínua expectativa do final dos tempos", a modernidade seria marcada pela expectativa de "um tempo novo", de um "Novo Mundo"13. Com isso, continua, a modernidade traria uma "decisiva inversão do Horizonte de Expectativa", representada por Koselleck no confronto entre duas Esperas, a de Lutero e a de Robespierre, isto é, a Espera pelo apocalipse e pela revolução respectivamente. Curioso é que enquanto Lutero compreendia o grande número de acontecimentos que marcaram o seu tempo como "uma abreviação temporal" que indicaria "que o fim do mundo se aproximava com grande velocidade, ainda que a data

\footnotetext{
${ }^{7}$ ARANTES, 0 novo tempo do mundo, 27

8 Idem, 28.

${ }^{9}$ Idem, 31; 33.

10 Idem, 31.

11 Idem, 32.

12 Idem, 36.

13 Idem, 39.
} 
permanecesse oculta"14, para Roberspierre seria o dever de todos os cidadãos acelerar o progresso preparado pela razão humana através da Revolução. Conforme citação de Koselleck destacada por Arantes: "Para Lutero, a abreviação do tempo é um sinal visível da vontade divina de permitir que sobrevenha o Juízo Final, o fim do mundo. Para Roberspierre, a aceleração do tempo é uma tarefa do homem, que deverá introduzir os tempos da liberdade e da felicidade"15. Diante disso, sintetiza Arantes, "esse Grande Teatro dos Últimos Dias foi aos poucos cedendo terreno a uma outra Espera, [...] onde se mesclam ciência racional do prognóstico político e visões de uma outra aceleração - pois agora se tratava de 'recuperar o atraso da razão"'16. Note-se que essa "transmutação do futuro profetizado em futuro prognosticável" indica que "a distância entre a consciência histórica e política moderna, de um lado, e a escatologia cristã, de outro, mostra-se menor do que em princípio se poderia supor", afinal "nada de fundamentalmente novo pode acontecer, seja o futuro perscrutado com a reserva do crente ou com o prosaísmo do calculista" 17.

0 ponto é que a "revelação do globo terrestre" possibilitada pelas Grandes Navegações permitiu que fosse generalizada a percepção da "contemporaneidade do não contemporâneo"18 ou ainda da "simultaneidade daquilo que não é contemporâneo"19. Isto é, quando se viu a partir da perspectiva europeia a América selvagem, interpretou-se que se estava a olhar para trás e este tipo de comparação ordenou a história do mundo, no sentido de que essa passou a ser "interpretada como um progresso para objetivos cada vez mais avançados." Com isso, continua Koselleck conforme a reconstrução de Arantes, "a noção de Progresso se torna um Horizonte", ou seja, torna-se o "postulado da aceleração" e, no caso "dos que haviam ficado para trás", o postulado do "alcançar ou ultrapassar" resultante do "impulso constante para a comparação progressiva" oriunda da "observação de que povos, estados, continentes, ciências corporações ou classes estavam adiantados uns em relação aos outros" 20 .

Se foi entre 1500 e 1800 que o tempo histórico adquiriu essa "qualidade inteiramente nova" 21 , isto é, nesse "intervalo pontuado por Renascimento, Descobertas e Reforma, sem falar na Grande Revolução, de cuja expansão napoleônica o próprio intelectual era testemunha e intérprete, mais adiante refratário"22 -, apenas tardiamente nos 1800, é que o Progresso foi "inventado ou descoberto". Dito de outro modo, apenas no século XVIII, que a burguesia ao transformar a história em movimento rumo a "uma abertura utópica do horizonte de expectativas" 23 e sem estar "consciente dessa transformação", inaugura, segundo Koselleck, não só os tempos modernos, mas a própria filosofia da história que se confunde com a modernidade e, portanto, com a transformação da história em progresso ${ }^{24}$. A "matrix do gênero filosofia da história" é o "planejamento utópico do futuro" e foi graças a um tal gênero que na interpretação de Arantes do pensamento de Koselleck, "a sociedade que se desenvolveu no século XVIII" pôde se entender como um "'mundo novo', reclamando intelectualmente o mundo inteiro" 25 .

Ao que parece, a concepção de história como progresso requer o gênero da filosofia da história para legitimar a falta de adequação e dessimetria entre experiência real, histórica e o

\footnotetext{
${ }^{14}$ KOSELLECK apud ARANTES, 0 novo tempo do mundo, 39.

15 Idem, 40.

${ }^{16}$ ARANTES, 0 novo tempo do mundo, 43.

17 KOSELLECK apud ARANTES, $O$ novo tempo do mundo, $43 \mathrm{n}$.

${ }^{18}$ ARANTES, 0 novo tempo do mundo, 45.

${ }^{19}$ KOSELLECK apud ARANTES, $O$ novo tempo do mundo, $46 \mathrm{n}$.

$20 \mathrm{I}$ dem, 45n.

${ }^{21}$ ARANTES, 0 novo tempo do mundo, 40.

22 Idem, 49.

${ }^{23}$ KOSELLECK apud ARANTES, 0 novo tempo do mundo, $37 \mathrm{n}$.

${ }^{24}$ Idem, 51.

${ }^{25}$ ARANTES, 0 novo tempo do mundo, $48 \mathrm{n}$.
} 
horizonte de Great Expectations, ou seja, o conteúdo profetizado pelos filósofos da história e para onde os Novos Tempos supostamente estariam a se mover. Legitimar na medida em que a filosofia da história ofereceria garantia racional à superação vindoura dessa falta de adequação entre experiência e expectativa; e o que é melhor oferece universalmente, dado que o sujeito dessa filosofia da história que é uma filosofia do progresso pretendia-se, segundo Koselleck, "a humanidade inteira"26. A fé, para me valer das palavras de Arantes, era a de que a elite, que seria elite por ser "moralmente justa e conforme a razão" estaria "em condições de rivalizar com a Providência, devidamente esclarecida e rebaixada, e assim planejar o futuro como censores que se encarregavam de discriminar o condenado e executar a sentença" 27 . A história como processo tem sentido, portanto, também moral e jurídico, já que esse processo tramitaria, por assim dizer, no "alto tribunal da razão", o que garantiria que o processo fosse mesmo um progresso. Daí, então, para voltar às palavras de Koselleck, que sob uma tal perspectiva a história só pudesse ser "concebida como filosofia da história, um processo de inocência que se deve realizar", e a história propriamente dita, por assim dizer, "pecado original da natureza", como algo que se devesse anular. 0 problema é que com isso a elite "moralmente justa e conforme a razão", em geral, se contentou em oferecer uma resposta moral - e moral, diga-se de passagem, não no sentido aristotélico, mas kantiano dada a fixação na intenção - fundamentada em prognósticos racionais de happy end, ao invés de os seus filósofos da história aperceberem-se no meio de uma guerra civil. 0 "novo homem" condizente aos novos tempos seria aquele que "acreditava poder aplicar sua garantia moral à história e à política [...] na medida em era filósofo da história"28. Diante disso, creio ser possível fazer esse acréscimo, que o nome dos filósofos da história virou legião.

Diferentemente do que à primeira vista se poderia supor, a fé e a defesa iluminista do progresso, de um futuro no qual não haveria o não contemporâneo no contemporâneo - por exemplo, não haveria o Brasil atual face à Alemanha atual - não se opõe ao capitalismo, antes o contrário essa fé mesma "legitima as hierarquias sociais e temporais" inerentes ao capitalismo. Mais do que isso: uma tal temporalização da história é uma imposição da "expansão mundial do sistema europeu de acumulação". "Por mais estranho que pareça", escreve Arantes, "esse sistema aparentemente absurdo de acumulação interminável como fim em si mesmo funciona desde o remoto século XVI"29. Seguindo a hipótese de Immanuel Wallerstein, Arantes defenderá que ao longo dos três séculos que separam os 1500 dos 1800, "a maioria das instituições básicas" do sistema capitalista já havia "sido estabelecida e consolidada" e, com isso, os "Estados supostamente soberanos" já começaram mal, isto é, já começaram "submetidos ao arcabouço de regras desse sistema"30.

0 ponto mais surpreendente desta história das ideias acerca da "moldura ideológica do capitalismo tardio" é que teria sido justamente com a Revolução Francesa que um conjunto de valores e regras básicos capaz de ser aceito ativamente pela classe esclarecida e, ao menos passivamente, pelo povo comum constitui-se numa "geocultura do progresso", na "fé geocultural na possibilidade de desenvolvimento", que seria "menos um suplemento espiritual de uma economia-mundo do que seu underside, sua fábrica submersa de visões acerca do modus operandi do sistema"31. Geocultura na medida em que essa fábrica de miragens em meio à desertificação da experiência real foi capaz de unificar o globo terrestre pela primeira vez e unificar a partir de um autoendimento utópico que escamoteou o estado permanente de crise em que o mundo ingressara com a "expansão permanente desde o nascedouro", de uma economia-mundo capitalista cujo fim "nonsense" seria o "da acumulação

\footnotetext{
${ }^{26}$ KOSELLECK apud ARANTES, 0 novo tempo do mundo, 53.

${ }^{27}$ ARANTES, $O$ novo tempo do mundo, 57.

28 KOSELLECK apud ARANTES, 0 novo tempo do mundo, 54.

${ }^{29}$ ARANTES, 0 novo tempo do mundo, 49.

${ }^{30}$ WALLERSTEIN apud ARANTES, $O$ novo tempo do mundo, 50 .

${ }^{31}$ ARANTES, $O$ novo tempo do mundo, 50.
} 
pela acumulação", o que torna "ainda mais surpreendente a entronização da ideia de 'progresso' como ideologia autojustificadora" dessa economia-mundo mesma ${ }^{32}$. "Noutras palavras", continua Arantes, a economia-mundo capitalista se legitimou "perante uma combinação paradoxal entre o sempre igual da acumulação como fim em si mesmo e um horizonte igualmente ilimitado de expectativas"33. O resultado de uma tal combinação paradoxal, segundo a reconstrução proposta do pensamento de Koselleck, foi que "o processo crítico do Iluminismo conjurou a crise na medida em que o sentido político dessa crise permaneceu encoberto. [...] A crise não era concebida politicamente, mas, ao contrário, permanecia oculta pelas imagens histórico-filosóficas do futuro": "A guerra civil foi reconhecida, mas minimizada" 34 .

Ante um tal "afresco", parece importante observar que a grande linha de frente dos "militantes burgueses", os propagadores ou efetivos filósofos da história - isto é, a elite intelectual, que "desenvolveu a consciência de encarnar o verdadeiro ser moral"35 -, foi a "moralização da política" ou, dito de outro modo, foi o ofuscamento moral do "estado de crise permanente no qual nos instalamos tão logo o globo terrestre foi unificado". Estado de crise permanente, posto que a economia-mundo capitalista impõe, como estamos cansados de saber, uma crescente hierarquização tanto econômica, quanto social, de modo que não só a diferença entre experiência e expectativa não parou de crescer como passou por uma "grande virada" que, por sua vez, diz respeito à "lógica mesma do Novo Tempo do Mundo" em que nos encontramos: uma dissociação tão completa entre experiência e expectativa, que acabou por reverter "todos os horizontes modernos de expectativa. Nada mais, nada menos"36. Assim, ao que parece, da Era de Great Expectations ingressamos na Idade de Diminishing Expectations, da visão de um horizonte aberto em direção ao novo mundo à visão de um horizonte achatado, em que a catástrofe se apresenta como algo insuperável de modo que a hora histórica em que vivemos sequer poderia ser dita como uma época, mas um prazo. Da espera do Apocalipse cristão para a espera do Novo Mundo, da espera do Novo Mundo para a espera de um Apocalipse no qual Deus está morto e não só a bomba atômica propriamente dita está pronta, como, em tempos de pandemia, cada indivíduo se torna ele mesmo uma bomba atômica em potencial, conforme a música do Sex Pistols, pelo simples fato de respirar. Como escreve Paulo Arantes, citando Günter Anders: "a ausência de futuro já começou"37.

E aqui chego a um dos pontos que propriamente me interessa nessa argumentação de Arantes, acerca da qual assumo os riscos de uma interpretação errônea, grosseira ou simplesmente outra. Pois se a "herança do Iluminismo" - e, portanto, a herança de todos nós intelectuais humanistas, em geral, de esquerda - é, como ele diz, "a utopia como resposta ao absolutismo", ou se pudermos atualizar, ao fascismo; essa herança iluminista, "que inaugurou o início dos tempos modernos - continua onipresente". Isso de um lado. Pois de outro, conforme afirma taxativamente, "ocorre que ainda vivemos sob a lei daquela guerra civil" 38 . E é justamente nesse ponto do ensaio "O novo tempo do mundo: a experiência histórica numa era de expectativas decrescentes", que não consigo deixar de me perguntar se condenação moral de Bolsonaro pelo seu "E daí?" - que, pelo que se pode acompanhar nas redes sociais, em tempos de confinamento, tornou-se o lema de denúncia da esquerda (ou de qualquer um

\footnotetext{
32 Idem, 38.

${ }^{33}$ ARANTES, 0 novo tempo do mundo, 48.

${ }^{34}$ KOSELLECK apud ARANTES, 0 novo tempo do mundo, 53; 54.

35 KOSELLECK apud ARANTES, 0 novo tempo do mundo, 59.

${ }^{36}$ ARANTES, 0 novo tempo do mundo, 55.

37 Idem, 39n.

38 Idem, 54.
} 
que tenha um respingo do que se costuma chamar humanidade) -, é uma estratégia política minimamente eficaz numa conjuntura em que esse mesmo "E daí?" se tornou ideologia entre pelo menos 30\%, quando finalmente já não podemos nos furtar em reconhecer que estamos em plena guerra civil . É justamente nesse ponto que não consigo deixar de me perguntar se nós da esquerda não passamos dos mesmos militantes burgueses de outrora cujo confronto com o poder soberano é meramente moral, o que de todo modo já não deveria permitir o refúgio da má-consciência de, em alguma medida, ter sido beneficiário dessa mesma guerra civil, antes da reviravolta, ou do agravamento representado pelos dois cavaleiros do apocalipse que mais uma vez se apresentam, mas agora sob a insígnia do bolsonarismo e do COVID-19. É justamente nesse ponto que não consigo deixar de me perguntar, se boa parte dos $30 \%$ do "eleitorado natural" da esquerda, porcentagem na qual me incluo, não acabou por reinventar o "Discurso da Sociedade Civil", condizente ao “"poder dos sem poder", cujo "projeto de resistência ao poder absoluto" parece em alguma medida pressupor que se está alocado numa espécie de "polo antipolítico da inocência"39 - e aqui, é justo dizer, apenas me valho das palavras de Arantes, embora já não siga o seu raciocínio. Em suma: perguntando-me se essa condenação moral universal compartilhada pela metade do país ao fascismo que elegeu Bolsonaro - e o qual, para minha surpresa confesso, agravou-se em tempos de pandemia -, não é tão excessivamente morna a ponto de poder ser apropriada por alguém da linhagem do governador João Dória, não é tão excessivamente morno a ponto de nos ter tornado membros em comunhão da Igreja do anjo de Laodiceia, a quem uma das cartas do Apocalipse (3:15-16) se endereça com a seguinte mensagem: "Conheço as tuas obras, que nem és frio nem quente; quem dera foras frio ou quente! Assim, porque és morno, e não és frio nem quente, vomitar-te-ei da minha boca". Pois se entendi bem Guattari: "O que não se quer ver é que a máquina fascista, em sua forma italiana ou alemã" - ou brasileira, poderíamos agora acrescentar -, na qual "as massas investiam uma fantástica pulsão de morte coletiva", é que

Ao reterritorializar seu desejo em um chefe, um povo, uma raça, [...] aboliam numa fantasia de catástrofe, uma realidade que detestavam e que os revolucionários não tinham sabido ou sequer querido tocar. A virilidade, o sangue, o espaço vital, a morte, substituíam, para elas, um socialismo demasiado respeitoso dos valores dominantes ${ }^{40}$. [grifo meu]

E é justamente por essas perguntas sem respostas, por essas perguntas talvez aparentemente excessivamente masoquistas, que não consigo compreender em absoluto como é possível reconhecer que se está no meio de uma guerra civil - agora, inclusive, contra um fascismo verde e amarelo recém-saído do armário e no contexto de uma pandemia que, segundo analogia estabelecida por Arantes numa live dias atrás ${ }^{41}$, pode ser compreendida como uma explosão de bombas atômicas em câmera lenta - e ainda assim acreditar que é possível lutar contra isso, lutar a luta perdida contra o lançar-se do abismo, sem lançar-se do abismo ele mesmo, sem ter de lançar mão do salto no escuro a apenas cem segundos para a plena meia noite (se formos levar a sério o Relógio do Juízo Final, sempre mencionado por Arantes). Pois segundo Safatle em artigo recente intitulado "Bem-vindo ao Estado suicidário", o "desejo de transformação e diferença” só se conjuga com "a gramática do sacrifício" quando se trata da "equação libidinal" referente ao fascismo ou, como ele diz, ao Estado suicidário. Certamente, conforme ele mesmo coloca, a lógica de que os escravos morram, só tem, no contexto brasileiro atual, a novidade de se aplicar a toda a população, como também parece certo que agora tenhamos tão somente chegado "à consagração final dessa lógica". Ainda

\footnotetext{
${ }^{39}$ Idem, 56.

${ }^{40}$ GUATARRI. Micropolítica do fascismo, 187.

41 Disponível em: https://www.youtube.com/watch?v=82mP0_Z169o\&t=25s Acesso: 16 de abril 2020.
} 
assim, a verdadeira questão que parece caber sob a perspectiva aqui desenvolvida é outra que a "verdadeira questão" colocada por ele. Ou seja: a questão não parece ser tanto a sobre "quem nunca paga pelo sacrifício enquanto prega o evangelho espúrio do açoite" - já que consiste numa pergunta retórica -, mas sim sobre quem nunca paga pelo sacrifício enquanto protesta contra o evangelho espúrio do açoite. E, ao que parece, a resposta inclui também a nós e os demais membros bastante heterodoxos da igreja do anjo de Laodiceia. Se for para levar a sério as alternativas postas por Safatle de fazer a "economia parar de vez utilizando todas as formas de contra violência popular"42 ou de construir redes efetivas de "solidariedade genérica" é importante ser honesto até o ponto de Terry Eagleton e reconhecer que sacrifício não é apenas uma noção "plena de masoquismo, de auto-aversão e uma antipatia mórbida para com tudo o que diz respeito à vida"; como se dissesse respeito de modo exclusivo àquilo que teria começado "como uma tentativa de aplacar um Deus selvagem" e culminado "com o apelo da pátria fascista"; que "o sacrífico não pode ser reduzido à autodestruição", dado que se trata de um "termo politético, que abrange uma série de atividades que não precisam ter sequer uma característica em comum"43. Afinal, conforme arremata no seu Radical Sacrifice: "É curioso que, quando o termo 'sacrifício' entra em discussão, a mente moderna e liberal associa espontaneamente à servidão doméstica e à morte em nome da causa da glória militar, e não à trajetória de Constance Markievicz ou à morte de Malcolm X"44.

\section{Agradecimentos}

Agradeço aos comentários sempre ponderados e lúcidos do meu amigo e parceiro intelectual Ricardo Henrique Resende de Andrade.

\section{Referências}

ARENDT, H. Eichmann em Jerusalém. São Paulo: Companhia das Letras, 1999.

ARANTES, P. 0 novo tempo do mundo. In: Arantes. $O$ novo tempo do mundo e outros estudos sobre a era de emergência. São Paulo: Boi Tempo, 2014.

BÍBLIA. Disponível em: https://www.bibliaonline.com.br/acf Acesso: 30 de abril 2020.

EAGLETON, T. Radical Sacrifice. London: Yale University Press, 2018.

GUATTARI, F. "Micropolítica do fascismo". In: Guattari. Revolução molecular. Trad. Suely Rolnik. São Paulo: Editora Brasiliense, 1985.

NIETZSCHE, F. W. Além do bem e do mal. Trad. Paulo César de Souza. São Paulo: Companhia das Letras, 1992.

NIETZSCHE, F. W. Genealogia da moral. Trad. Paulo César de Souza. São Paulo: Companhia das Letras, 1998.

SAFATLE. Bem-vindo ao Estado suicidário. Disponível em: https://n-1edicoes.org/004 Acesso: 25 de abril 2020.

\footnotetext{
42 SAFATLE. Bem-vindo ao Estado suicidário. Disponível em: https://n-1edicoes.org/004 Acesso: 25 de abril 2020.

${ }^{43}$ EAGLETON. Radical Sacrifice, 15.

${ }^{44}$ Idem, 14
} 
10 | COVID-19 e a aceleração do achatamento do horizonte de expectativa

SAFATLE, V. Entrevista. Disponível em: https://www.cartacapital.com.br/politica/bolsonarose-ve-a-frente-de-uma-revolucao-em-marcha-e-nao-vai-parar/ Acesso: 27 de abril 2020.

SAFATLE, V. Preparar-se para a guerra. Disponível em: https://brasil.elpais.com/opiniao/2020-04-20/preparar-se-para-a-guerra.html Acesso: 20 de abril 2020. 